\title{
Desertification of Iran in the early 21th century assessed via climate and vegetation indices
}

\author{
Hadi Eskandari Damaneh ${ }^{1}$, Hamid Gholami², Matt W. Telfer ${ }^{3}$, Jesus Rodrigo-Comino ${ }^{4}$, \\ and John Jansen ${ }^{5}$ \\ ${ }^{1}$ university of Hormozgan \\ ${ }^{2}$ University of Hormozgan \\ ${ }^{3}$ Plymouth Univ \\ ${ }^{4}$ Universidad de Malaga Facultad de Filosofia y Letras \\ ${ }^{5}$ Czech Academy of Sciences
}

June 9, 2020

\begin{abstract}
Remote sensing of specific climatic and biogeographical factors is an effective means of evaluating the desertification status of dryland regions affected by negative human impacts. Here, we identify and analyse land desertification trends in Iran via a combination of three indices of vegetation (NPP — net primary production, NDVI — normalized difference vegetation index, and LAI — leaf area index); and two climate indices (LST-land surface temperature, and P — precipitation) during the period 2001-2015. The Mann-Kendall non-parametric test, the Theil-Sen estimator, and a simple linear regression method were then applied to identify trends and to map regions of Iran that are susceptible to desertification. Our results show that an area of $680,000 \mathrm{~km} 2(\sim 56 \%)$ of Iran is classified with a very high level, indicating that a large fraction of Iran is susceptible to land desertification. We suggest that spatial and temporal trends in the three vegetation indices (NPP, NDVI, and LAI) and the two climate indices (LST and P) are a cost-effective choice for the prediction and management of future environmental trends in the world's developing regions, and are a step towards achieving land-use sustainability by helping to locate the most degraded areas.
\end{abstract}

\section{Hosted file}

LDD.docx available at https://authorea.com/users/331599/articles/458215-desertification-ofiran-in-the-early-21th-century-assessed-via-climate-and-vegetation-indices 


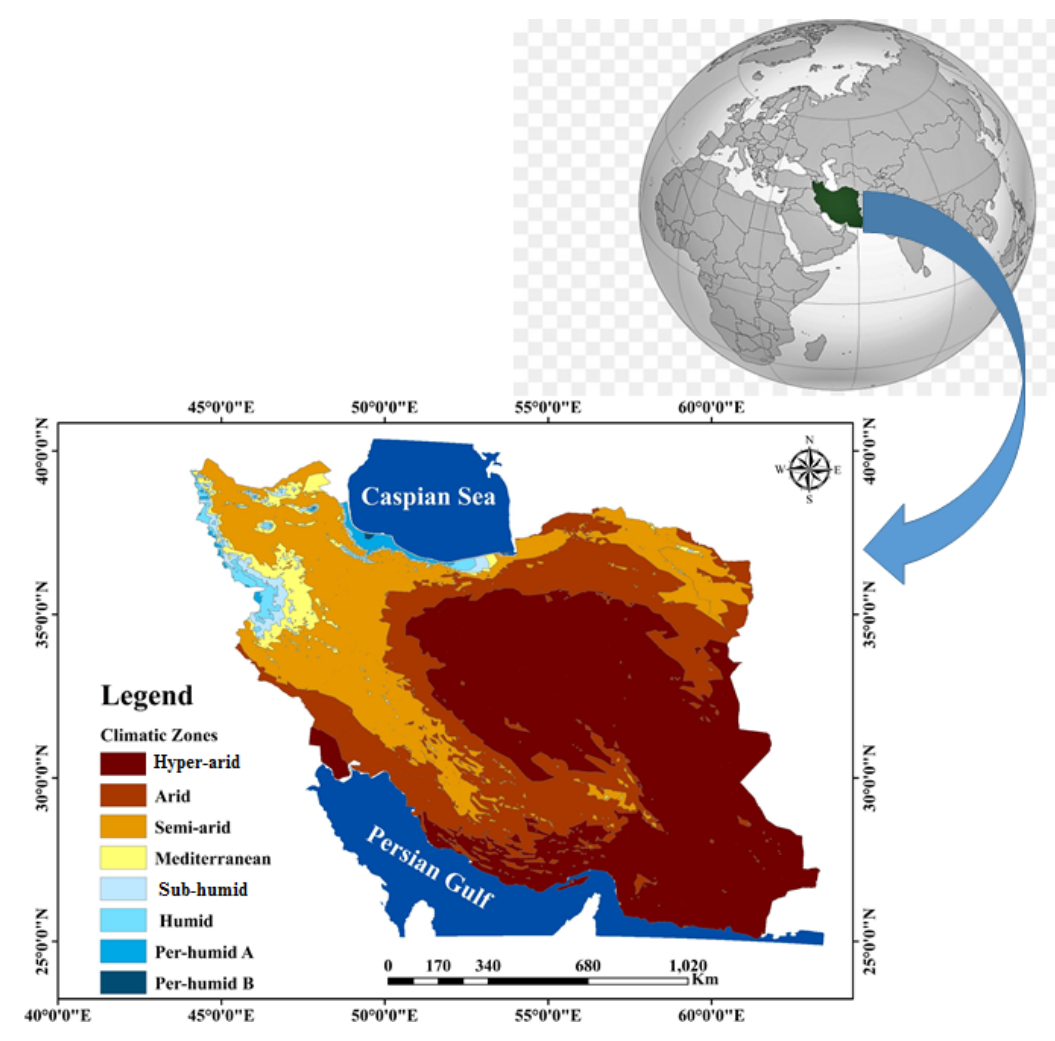



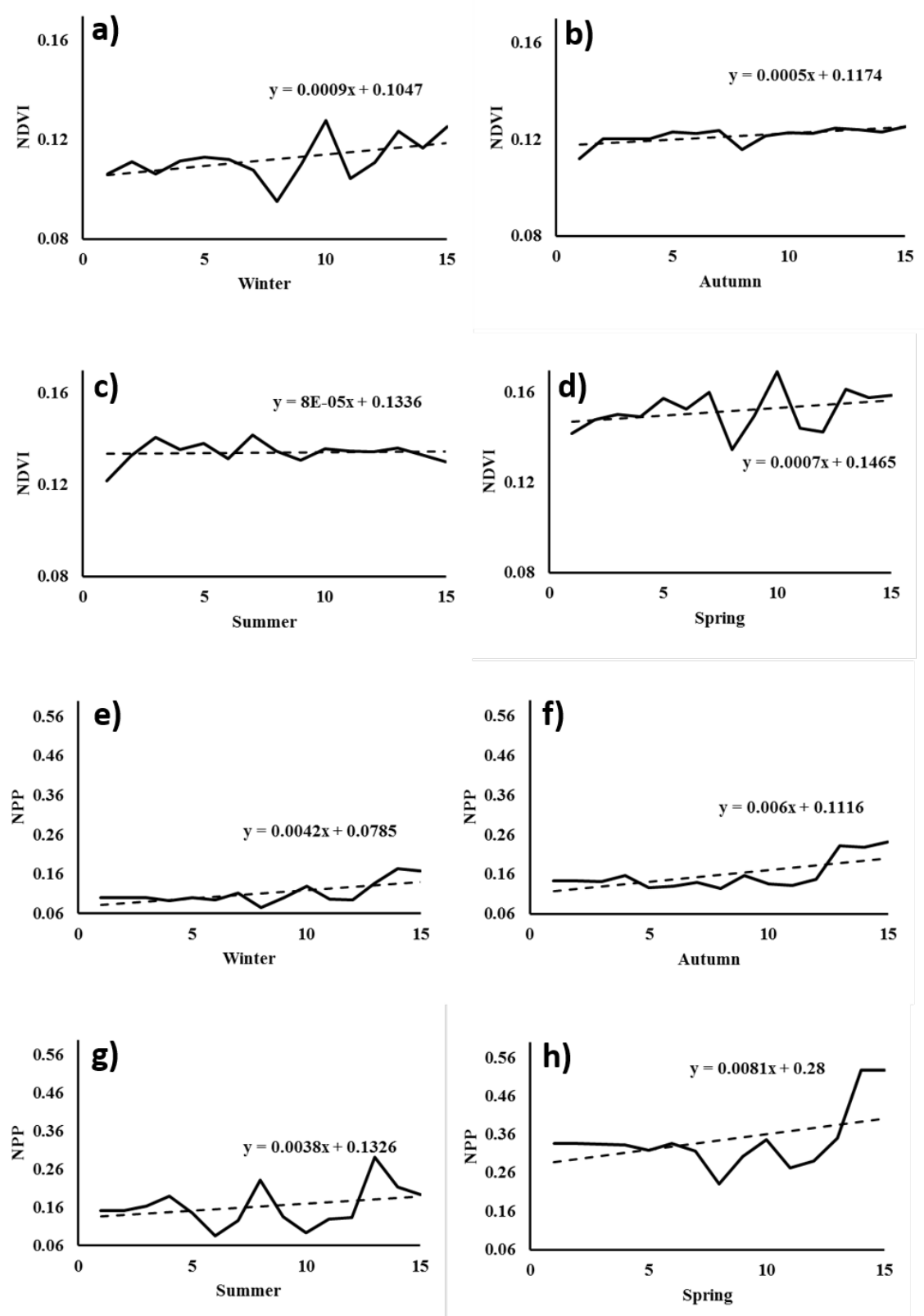

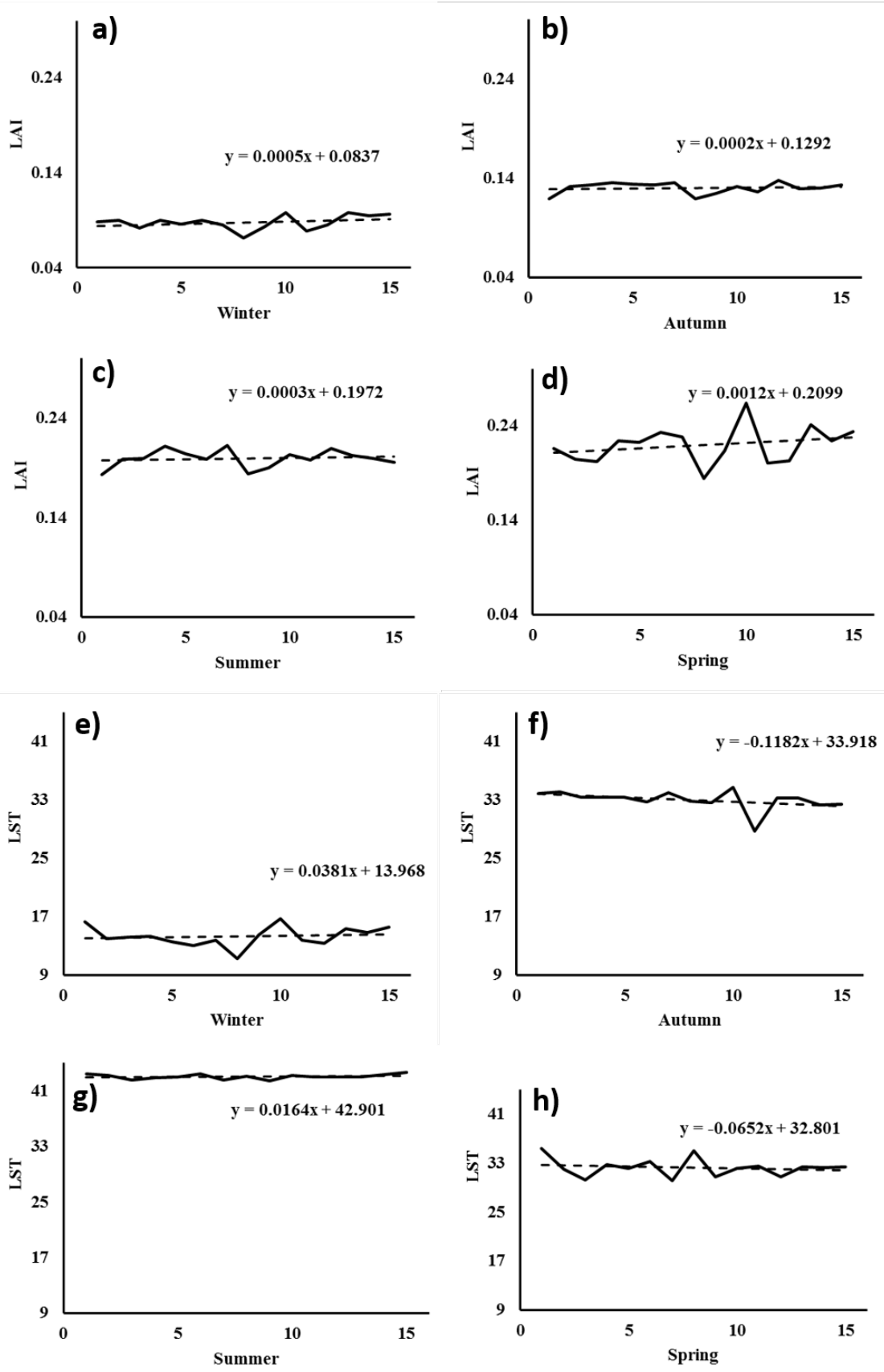

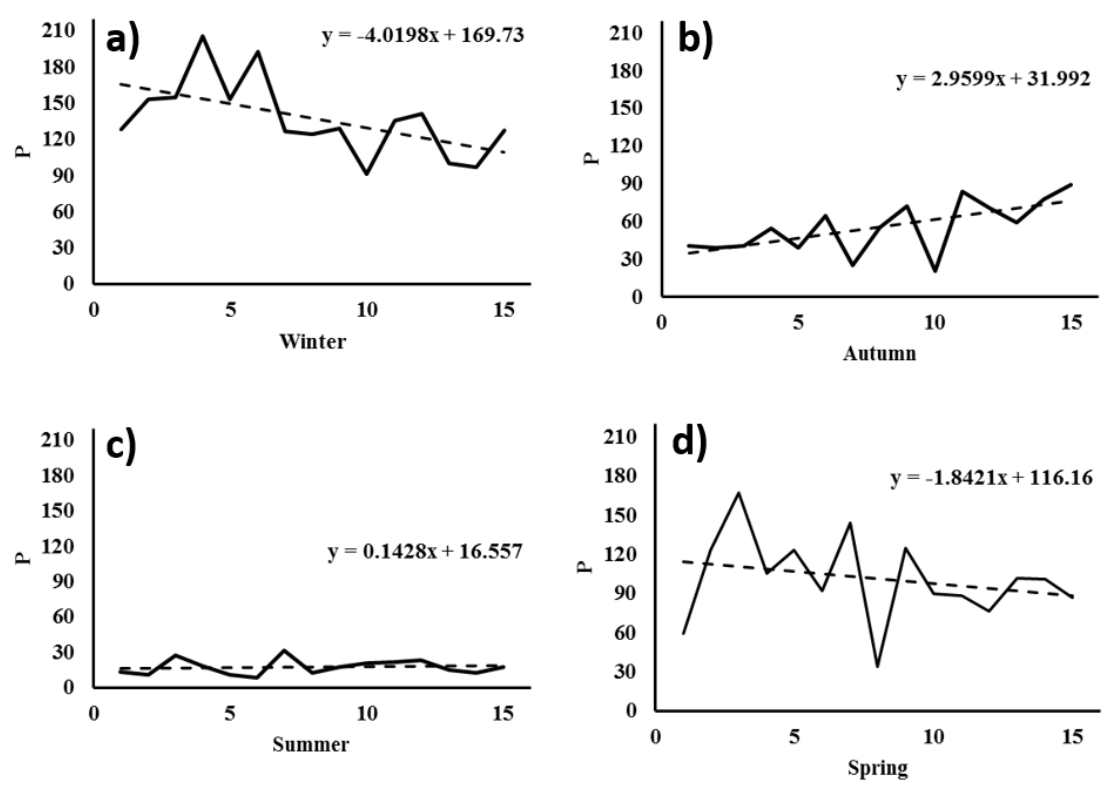

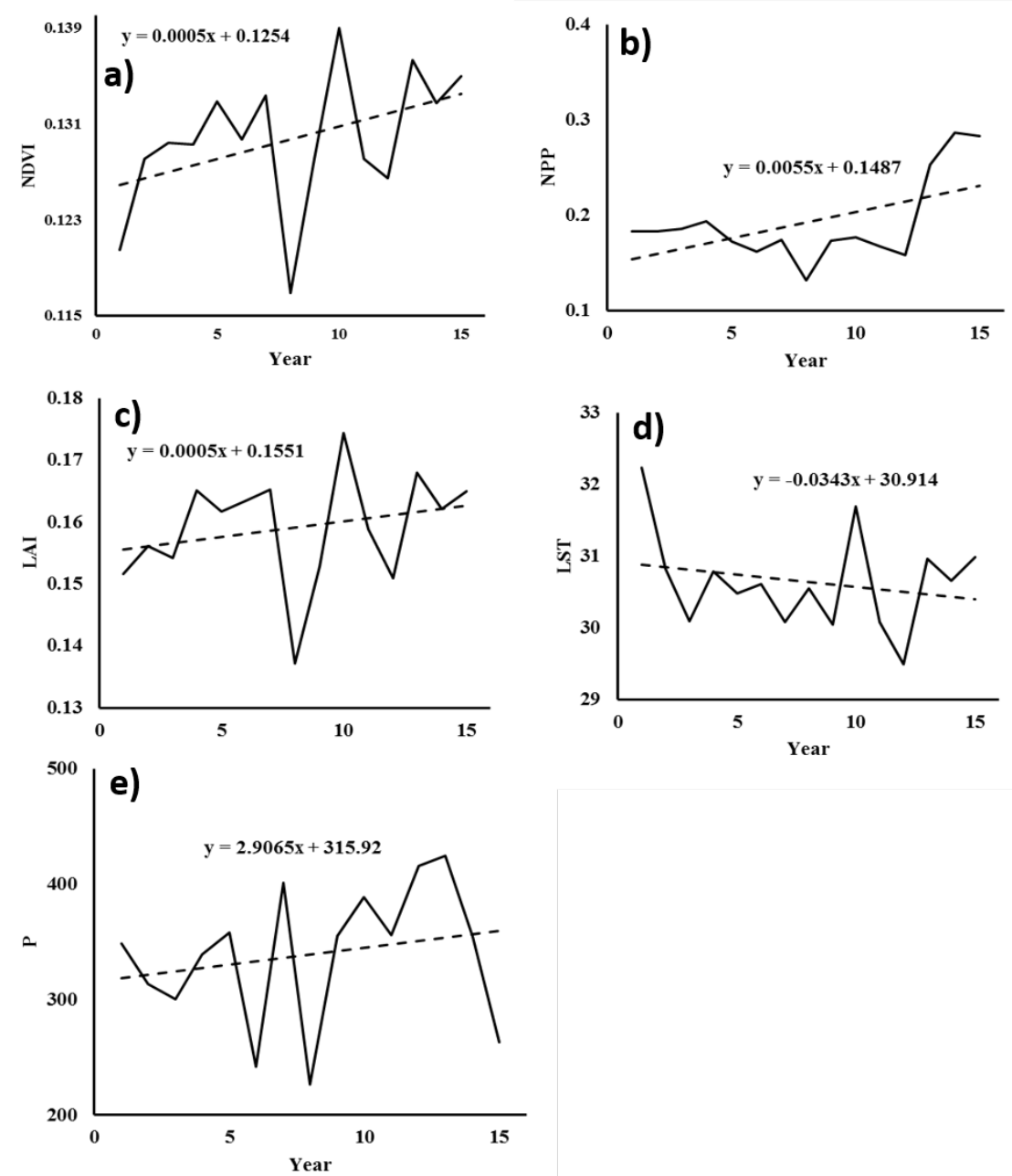
a)

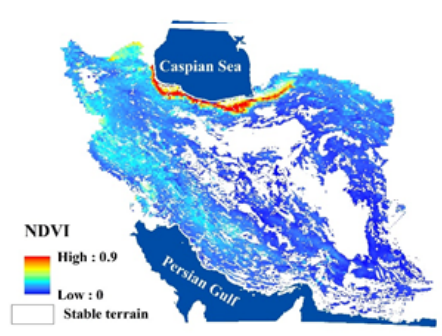

c)

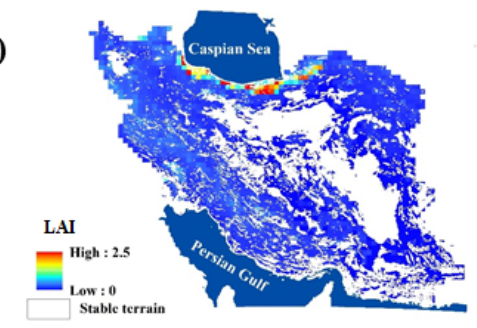

e)
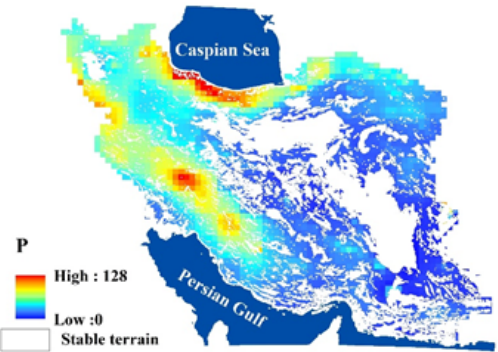

b)

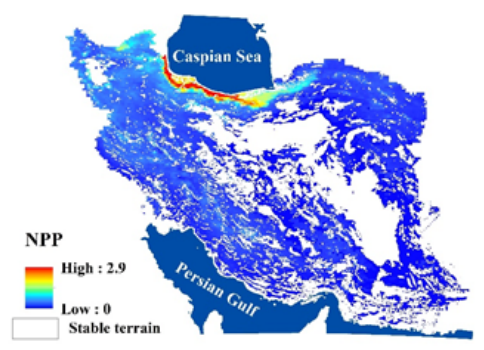

d)

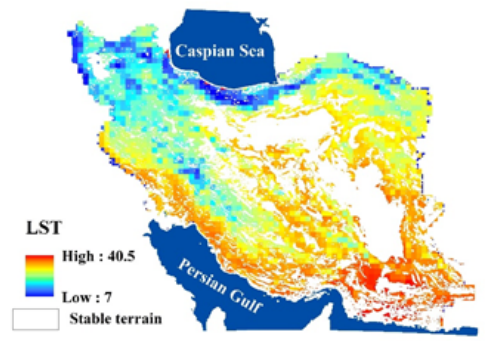


a)

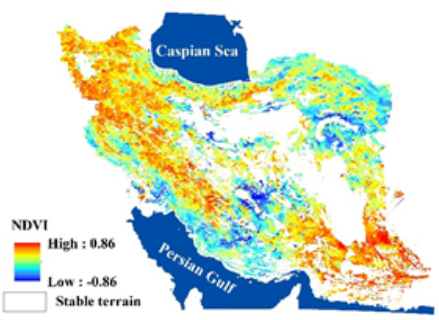

c)

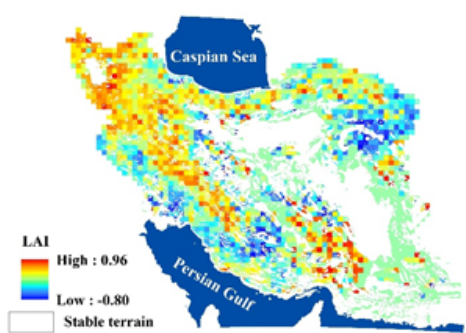

e)

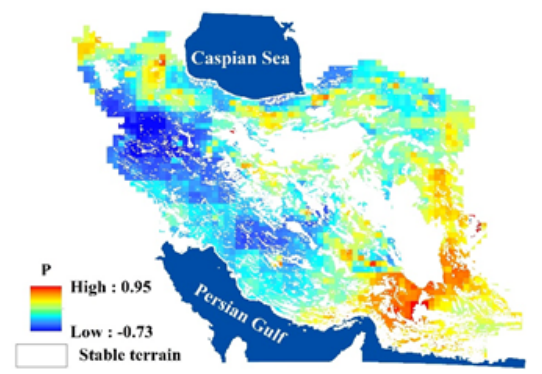

b)

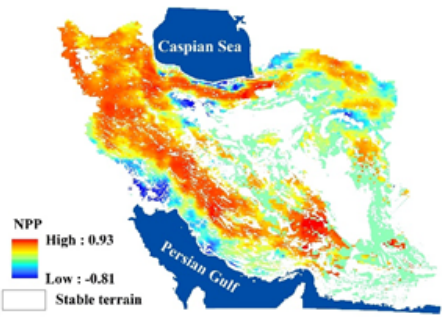

d)

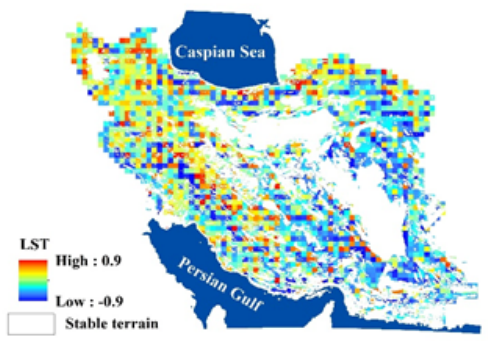

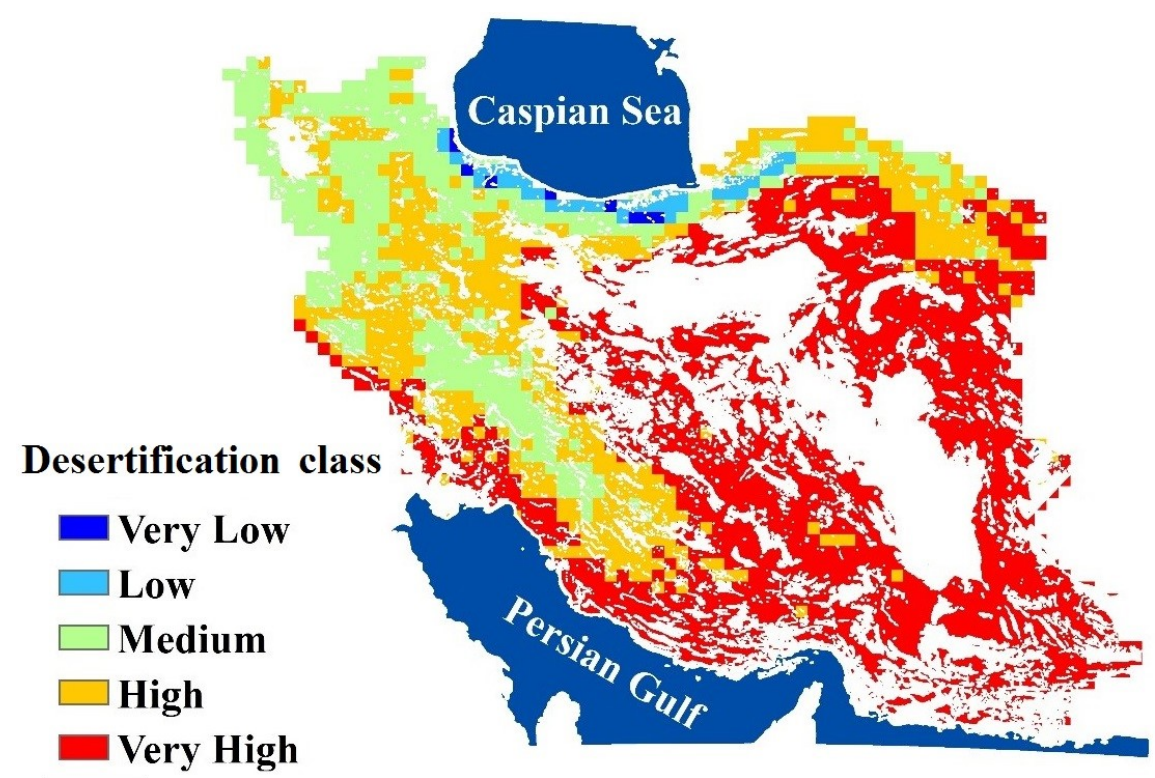
Stable terrain 